\title{
Modeling and Simulation of the Wind Energy Electric Conversion System using MATLAB/Simulink
}

\author{
Swapnil S. Sonekar \\ PG Scholar, Department of Electrical Engineering \\ Shri Sai College of Engineering \& Technology \\ Bhadrawati, Maharashtra, India.
}

\author{
U. G. Bonde \\ Professor, Department of Electrical Engineering \\ Shri Sai College of Engineering \& Technology \\ Bhadrawati, Maharashtra, India.
}

\begin{abstract}
Among several forms of renewable sources of energy, specifically wind energy conversion system is the most cost effective and technologically improvable. In variable speed operation, it is important that the generated power from PMSG should be optimized. Therefore in order to capture as much power as possible from wind during change in wind speed, maximum power point tracking controller is implemented. Among several methods, the most efficient method of MPPT technique is Perturbation and observation (P\&O) which has its own virtues. Here simulation evaluation is done to know the working of MPPT and successfully optimize the generated power during a step change in wind speed. In addition to power optimization, variation in load as well as wind speed during variable speed operation, results drift in system voltage. Therefore in order to reduce the change in system voltage and frequency to the smallest possible value, a voltage frequency controller is required. The Voltage frequency controller receives/supplies active/reactive power and hence system voltage is maintained almost constant around it's reference value. For this three phase three wire systems is considered. The performance of the system is also evaluated for change in load.

A PMSG based stand-alone WECS with boost converter is designed, simulated and modeled using the power system block set in MATLAB R2016a to obtain the results. The simulated waveforms validate the system performance.
\end{abstract}

Keywords- Wind energy conversion system(WECS), Maximum power point tracking (MPPT), Perturb and observe $(P \& O)$, Incremental conductance (INC).

\section{INTRODUCTION}

One of the major concerns in the power sector is the dayto-day increasing power demand but the unavailability of enough resources to meet the power demand using the conventional energy sources. Demand has increased for renewable sources of energy to be utilized along with conventional systems to meet the energy demand. Renewable sources like wind energy and solar energy are the prime energy sources which are being utilized in this regard. The continuous use of fossil fuels has caused the fossil fuel deposit to be reduced and has drastically affected the environment depleting the biosphere and cumulatively adding to global warming.

Wind energy is abundantly available that has made it possible to harvest it and utilize it properly. Wind energy can be a standalone generating unit or can be a grid connected generating unit depending on the availability of a grid nearby. Thus it can be used to power rural areas where the availability of grids is very low. Another advantage of using wind energy is the portable operation whenever wherever necessary. In order to tackle the present energy crisis one has to develop an efficient manner in which power has to be extracted from the incoming wind. The power conversion mechanisms have been greatly reduced in size in the past few years. The development in power electronics and material science has helped engineers to come up very small but powerful systems to withstand the high power demand. But the disadvantage of these systems is the increased power density. Trend has set in for the use of multi-input converter units that can effectively handle the voltage fluctuations. But due to high production cost and the low efficiency of these systems they can hardly compete in the competitive markets as a prime power generation source.

The constant increase in the development of the solar cells manufacturing technology would definitely make the use of these technologies possible on a wider basis than what the scenario is presently. The use of the newest power control mechanisms called the Maximum Power Point Tracking (MPPT) algorithms has led to the increase in the efficiency of operation of the wind modules and thus is effective in the field of utilization of renewable sources of energy [3], [8].

This paper is organized as follows: Configurations of Variable Speed Wind Conversion Systems will be presented and discussed in section 2. In section 3, the PMSG voltage control is presented. Whereas in section 4 , a voltage source inverter model is discussed. Of course, the simulation results in Matlab/Simulink environment of the full WECS are presented and talked over in section 5, so as to evaluate its performance. Eventually, conclusion is presented in section 6 .

\section{SYNCHRONOUS GENERATORS}

The stator of the synchronous generators holds the set of three-phase windings that supply the external load. The rotor, on the other hand, is the source of the machine's magnetic field. The magnetic field is either supplied by a direct current (DC) flowing in a wound field or a permanent magnet.

Fig.1 illustrates a typical setup of a wind turbine with a wound field synchronous generator (WFSG) connected to the grid through power electronic converters. The WFSG has high machine efficiency, and the power electronic converters allow direct control over the power factor. However, because of the winding circuit in the rotor, the size of the WFSG can be rather large. Another drawback of the configuration in Fig.2 is that in order to regulate the active and reactive power, the power electronic converter must be sized typically 1.2 times the rated power. Thus, the use of the WFSG leads to a bulky system [6]. 
Wound Field Synchronous Generator (WFSG)

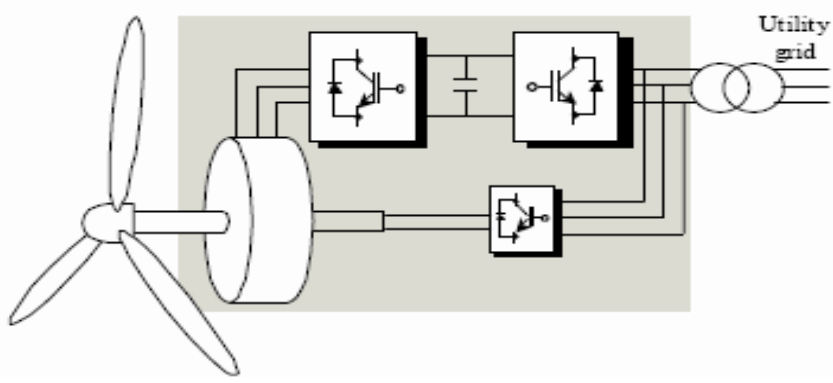

Fig.1. A typical fixed speed wind turbine configuration.

The stator of the turbine is connected to the utility grid through two back-to-back pulse width modulated (PWM) converters. The main task of the stator side converters is to control the electromagnetic torque of the turbine. By adjusting the electromagnetic torque, the turbine can be forced to extract maximum power. The rectifier connects the rotor and the utility; it converts the alternating current (AC) from the utility grid into a direct current into the rotor windings. DC current flows through the rotor windings and supplies the generator with the necessary magnetic field for operation. Permanent magnet synchronous generators (PMSG) are common in low power, variable speed wind energy conversion systems [11]. The advantages of using PMSGs are its high efficiency and small size. However, the cost of the permanent magnet and the demagnetization of the permanent magnet material should be considered [6].

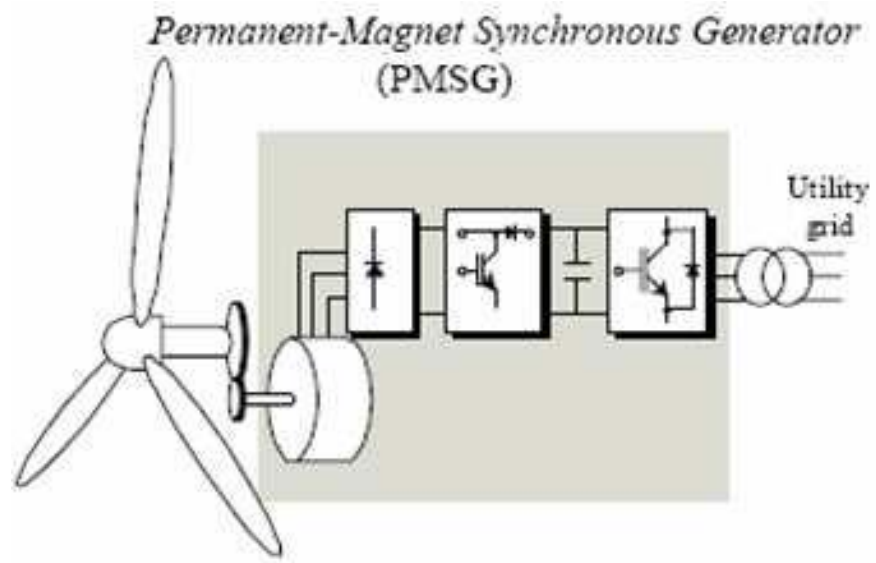

Fig.2. Common system setup with a permanent magnet wind turbine (generator is connected to the utility through a diode rectifier, boost converter and an inverter).

Fig. 2 and 3 illustrate two common grid connection configurations of PMSG wind turbines. In Figure 2.4, the stator windings are connected to the utility grid through a diode rectifier, boost converter, and a PWM inverter. The diode rectifier rectifies the variable frequency and magnitude output $\mathrm{AC}$ voltages from the turbine. The boost converter on the other hand controls the electromagnetic torque of the generator. To boost the wind energy conversion efficiency of the system, the boost converter is coupled with a maximum power point tracking algorithm. At the grid side, the power inverter regulates the varying DC link voltage and controls the output power factor [6].

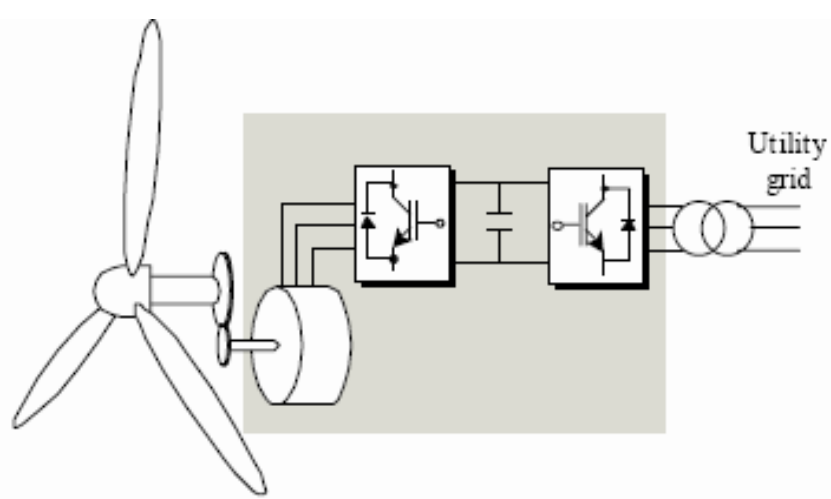

Permanent-Magnet Synchronous Generator with PWM converter.

Fig.3. Common system setup with a permanent magnet wind turbine (generator is connected to the utility through two back-to-back converters).

Fig. 2 and 3 illustrate two common grid connection configurations of PMSG wind turbines. In Figure 2.4, the stator windings are connected to the utility grid through a diode rectifier, boost converter, and a PWM inverter. The diode rectifier rectifies the variable frequency and magnitude output AC voltages from the turbine. The boost converter on the other hand controls the electromagnetic torque of the generator. To boost the wind energy conversion efficiency of the system, the boost converter is coupled with a maximum power point tracking algorithm. At the grid side, the power inverter regulates the varying DC link voltage and controls the output power factor [6].

The stator windings of the PMSG wind turbine in Fig. 3 are connected to the grid through two back-to-back PWM power converters. Maximum power point tracking algorithms are usually implemented in the utility side converter, but can generally implemented in either converter. The PWM modulation used in this configuration reduces the current harmonic component in the input and output of the system. By using PWM converters, there is also reduced torque pulsation on the generator and the output power quality is improved.

\section{PMSG VOLTAGE CONTROL}

The mechanical power produced by a wind turbine is given as bellow,

$$
P=\frac{1}{2} \rho \pi R^{2} C_{P}(\lambda, \beta) \vartheta_{w}^{3}
$$

Where, $\rho$ is the air density $(\mathrm{kg} / \mathrm{m} 3), \mathrm{R}$ is the radius of the turbine blade $(\mathrm{m}), \mathrm{Vw}$ is the wind velocity $(\mathrm{m} / \mathrm{s}), \mathrm{Cp}$ is the turbine power coefficient which is a measure of turbine power conversion efficiency and is a function of tip speed ratio $(\lambda)$ and blade pitch angle $(\beta)$.

Tip speed ratio is defined as the ratio of the blade tip speed to the wind velocity striking the blades and can be expressed as [3],

$$
\lambda=\frac{\omega_{R}}{\vartheta_{w}}
$$

Where, $\omega$ is the mechanical angular speed of the turbine $(\mathrm{rad} / \mathrm{s})$.

To obtain the maximum power, $\mathrm{Cp}$ should achieve its maximum value for a given wind turbine. It is apparent from the $\mathrm{Cp}-\lambda$ curve shown in Fig.4 that the maximum $\mathrm{Cp}(\mathrm{Cp}$ $\max$ ) occur at an optimum value of tip speed ratio $(\lambda \circ \mathrm{opt})$. 


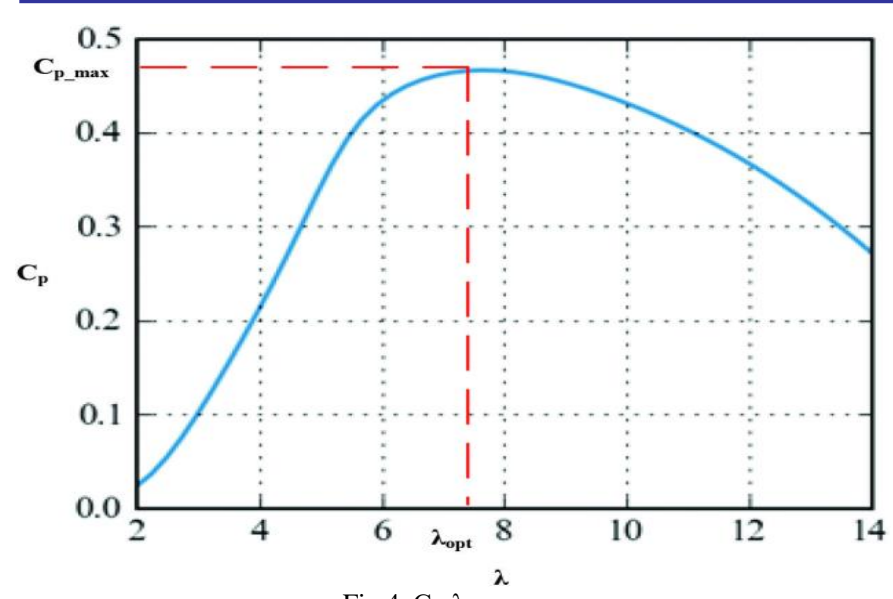

Fig.4. Cp $\lambda$ curve.

The Cp-9_w characteristics of an Enercon E40 $2.3 \mathrm{~kW}$ gearless, variable speed, variable pitch control turbine data [4] is plotted in Fig.5 as power coefficient Cp versus $\vartheta_{-} \mathrm{W}$ and $\mathrm{P}$

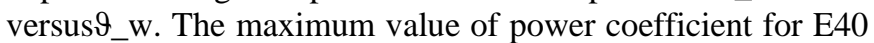
is 0.5 . At this point, the wind turbine is getting its rated power at the wind speed of $16 \mathrm{~m} / \mathrm{sec}$ (shown as a green line in Fig. 5(b)) with power coefficient $\mathrm{Cp}=0.23$ (as shown in Fig.5(a)).

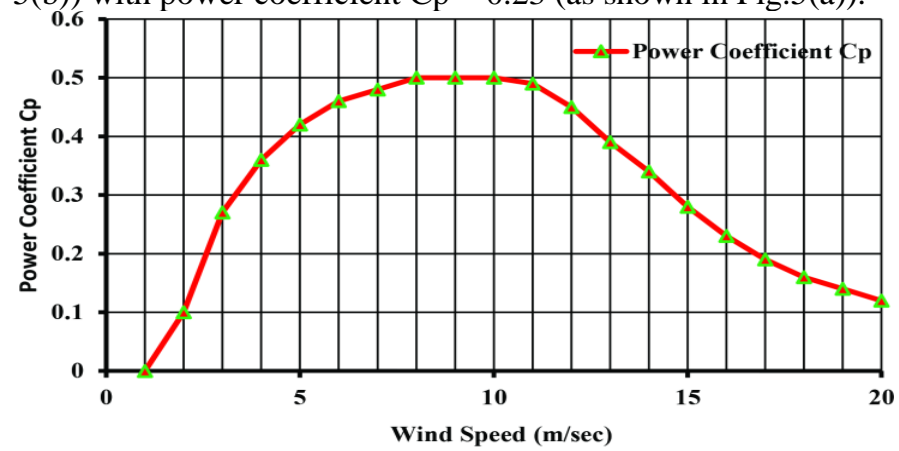

(a)

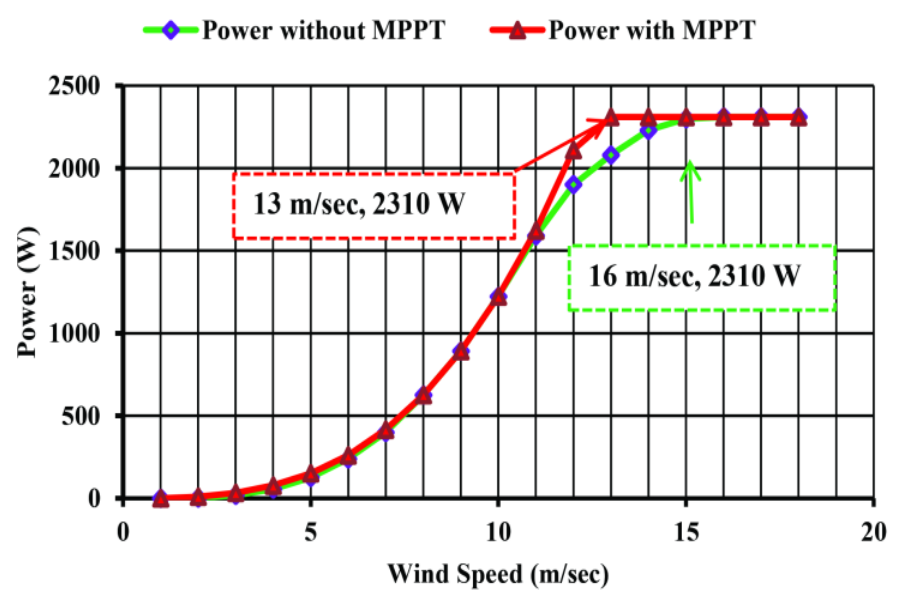

(b)

Fig.5.The characteristics of an Enercon E40 $2.3 \mathrm{~kW}$ gearless, variable speed, variable pitch control turbine. Curve (a) $\mathrm{Cp}^{-} \mathrm{vw}$ Curve (b) $\mathrm{P}$-vw Curve.

The main aim in MPPT system is to control the duty cycle (D) of the converter used source side. In the source side we use a convertor to enhance the output voltage and by changing the duty cycle of the converter appropriately the source impedance can be matched with the load impedance.
Among all MPPT techniques, the MPPT techniques which are to be discussed in this paper are:

\section{A. Perturbation and observation ( $P \& O) M P P T$ algorithm}

The HCS is also called perturbation and observation $(\mathrm{P} \& \mathrm{O})$ since it observes the perturbation in power and according to that it provides the corrections in the particular parameter like duty cycle of the DC-DC converter to control the dc voltage or to regulate current [16-18] in order to adjust the rotor speed and track the MPP. This method is based on perturbing control variable in arbitrary small steps, and the next perturbation is decided on observing the changes in power curve due to preceding perturbation. $\mathrm{P} \& \mathrm{O}$ approach is a widely used MPPT algorithm because of its simplicity and absence of mechanical speed sensor or anemometer for implementation. This method suffers from following two drawbacks: sluggish response especially for low step size and inefficient operation under rapid wind variations [19].
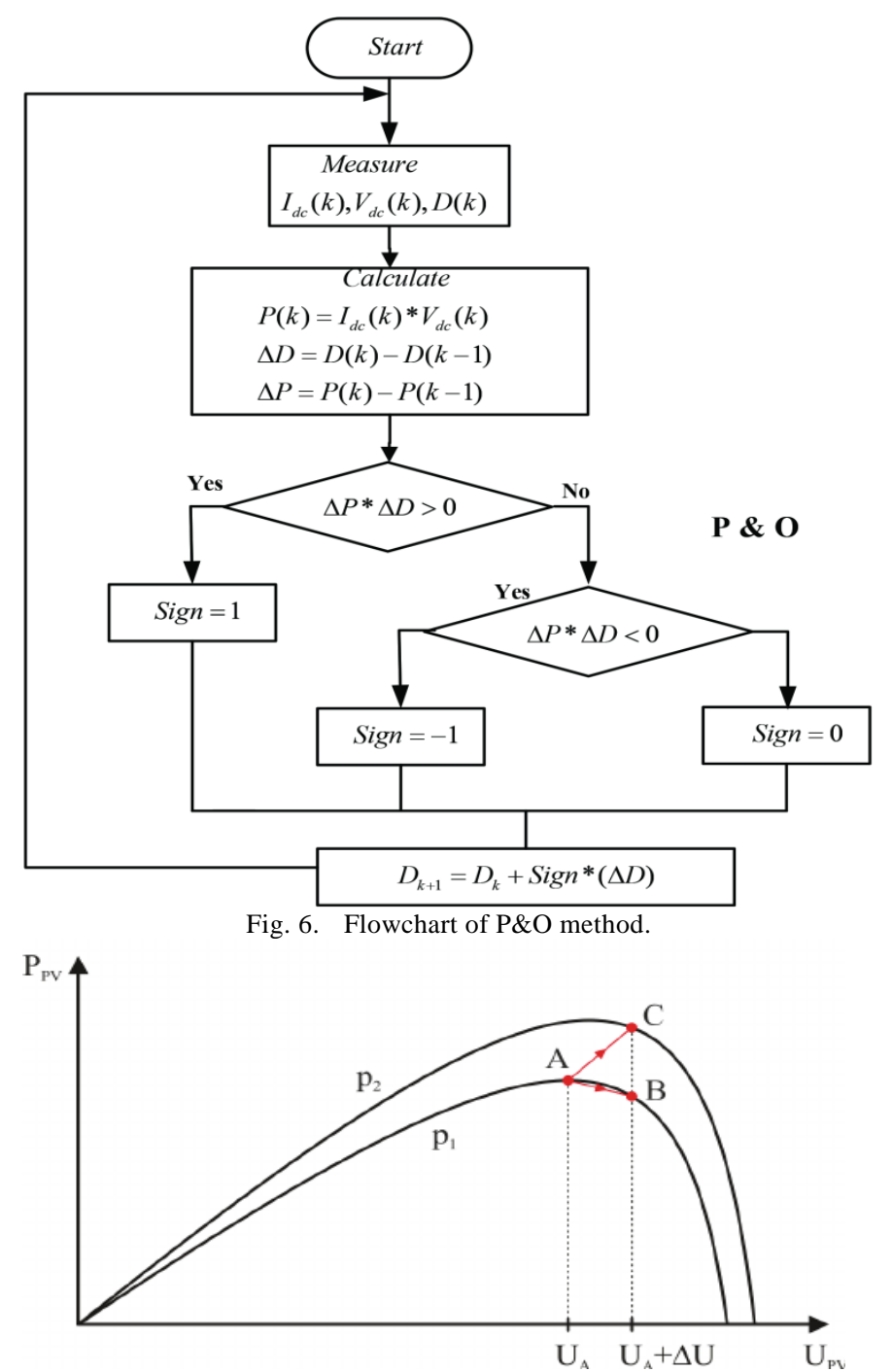

Fig. 7. Divergence of $\mathrm{P} \& \mathrm{O}$ from MPP.

Under sudden changing atmospheric conditions $\mathrm{P} \& \mathrm{O}$ method does not respond well as illustrated in figure 6. Due to small perturbation of $\Delta \mathrm{V}$ in the $\mathrm{PV}$ voltage $\mathrm{V}$ under constant atmospheric conditions the operating point moves 
from A to B. Since power decreases to B so according to $\mathrm{P} \& \mathrm{O}$ algorithm the perturbation should be reversed. And when the power curve shifts from $\mathrm{P}_{1}$ to $\mathrm{P}_{2}$ due to increase in irradiance the operating point will change from A to $\mathrm{C}$. Now there is increase in power so again according to $\mathrm{P} \& \mathrm{O}$ algorithm the perturbation should be kept same which results in the divergence of operating point from Maximum Power Point [3], [4] and hence calculates the wrong MPP. To avoid this problem we can use incremental conductance method to track MPP correctly even under rapid change in irradiance.

\section{B. Incremental Conductance (INC)s}

The incremental conductance method is based on the fact that the slope of the P vs. V (I) of the wind module is zero at the MPP, positive (negative) on the left of it and negative (positive) on the right of MPP. This technique deals with the sign of $\mathrm{dP} / \mathrm{dV}$ without a perturbation which overcome the limitations of $\mathrm{P} \& \mathrm{O}$ technique [5].

$\mathrm{dP} / \mathrm{dV}>0 \quad$ left side of the curve

$\mathrm{dP} / \mathrm{dV}<0 \quad$ right side of the curve

$\mathrm{dP} / \mathrm{dV}=0 \quad$ peak of the curve 8):

The above expressions can be expressed as (shown in fig.

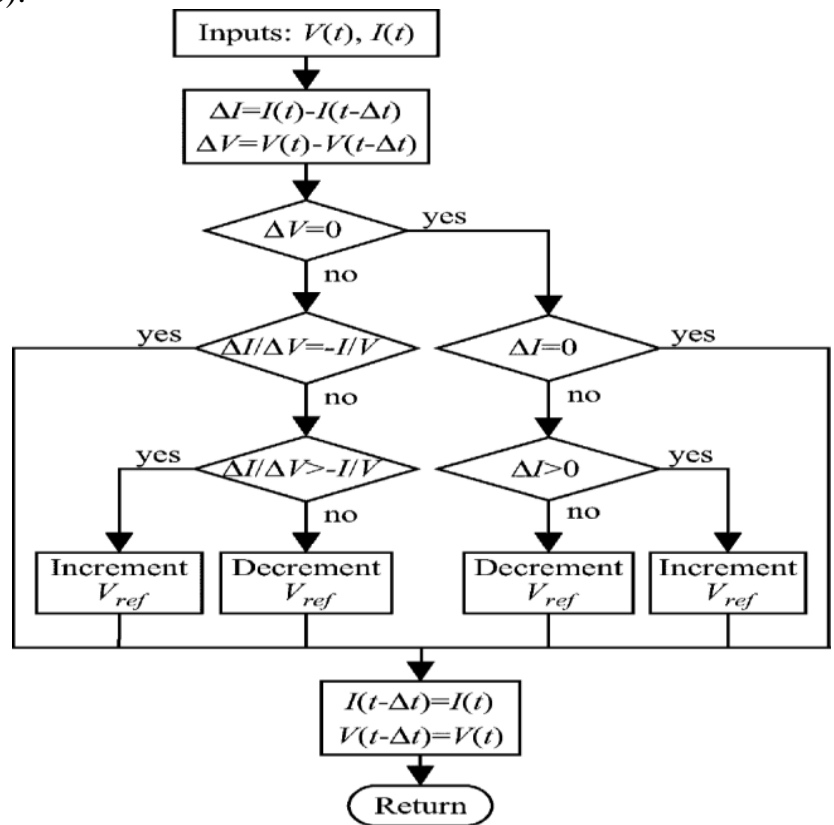

Fig. 8. Flow chart of Incremental Conductance method.

$$
\frac{d P}{d V}=\frac{d(I V)}{d V}=I+V \frac{d I}{d V} \cong I+V \frac{\Delta I}{\Delta V}
$$

For MPP by putting $\frac{\mathrm{dP}}{\mathrm{dV}}=0$, we get,

Hence,

$$
\mathrm{I}+\mathrm{V} \frac{\Delta \mathrm{I}}{\Delta \mathrm{V}}=0
$$

$\Delta \mathrm{I} / \Delta \mathrm{V}=-\mathrm{I} / \mathrm{V}$, At MPP

$\Delta \mathrm{I} / \Delta \mathrm{V}>-\mathrm{I} / \mathrm{V}$, Left of MPP

$\Delta \mathrm{I} / \Delta \mathrm{V}<-\mathrm{I} / \mathrm{V}$, Right of MPP

Where,

$\mathrm{I} / \mathrm{V}$ is instantaneous conductance,

$\Delta \mathrm{I} / \Delta \mathrm{V}$ is incremental conductance,
VREF is reference voltage at which wind terbine is to be operated.

According to above equations the maximum power point can be tracked by comparing the $\mathrm{I} / \mathrm{V}$ to $\Delta \mathrm{I} / \Delta \mathrm{V}$ as shown in the flow chart (fig. 8).

\section{VSI MODEL}

The VSI used in this work converts DC voltage to threephase AC voltages. Fig. 6 shows the detail circuit of the inverter. The power part of the inverter is composed of three arms consisting each one two switches. Each switch is composed of transistor (IGBT, MOSFET...) and of a diode coupled in parallel. The LC filter is connected to the inverter output, it's designed to reduce high order harmonics produced by the pulse-width modulation (PWM) inverters. [1][16][10]

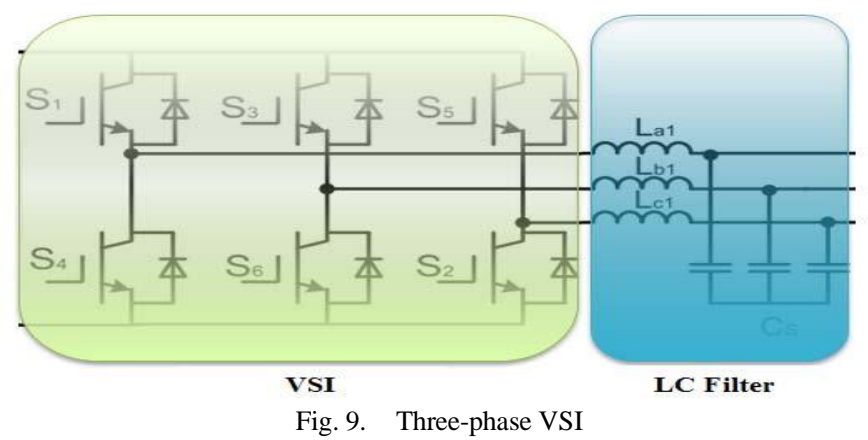

\section{A. PWM Control}

To generate an analog signal using a digital source a pulse width modulation signal is mostly used. Two main components define the behavior of PWM signal which are duty cycle and a frequency. The interest of the PWM is to provide a variable DC voltage from a fixed DC voltage source. PWM decreases the Total Harmonic Distortion (THD) of load current. The THD requirement can be met when the output of a PWM inverter is filtered since the unfiltered output of a PWM based inverted will have a relatively high distortion.

There are different types of PWM schemes, the most used ones being sinusoidal PWM (SPWM), hysteresis PWM (HPWM), space vector modulation (SVM) and optimal PWM [13]. The inverter switching, used in this studied system, is controlled by the SPWM. The high-frequency triangular carrier wave VCR is compared with a sinusoidal reference Vm of the desired frequency (shown in Fig.7) to realize SPWM and generate the gating signal for the transistors (shown in Fig.11).

\section{B. LC Filter}

The filter is an essential element after semiconductor converter. The effect caused by switching semiconductor devices on other devices is reduces by filter. It delivers a sinusoidal output current with THD less than $5 \%$ [11]. Consequently, the low-pass LC filter is designed so that the cut-off frequency, fC is higher than the load current and voltage frequency and lower than the inverter switching frequency.

\section{SIMULATION RESULT}

The power system is simulated in Matlab/Simulink power system toolbox software. In this work, the simulation model for the full WECS power system components is designed (shown in Fig.10). 


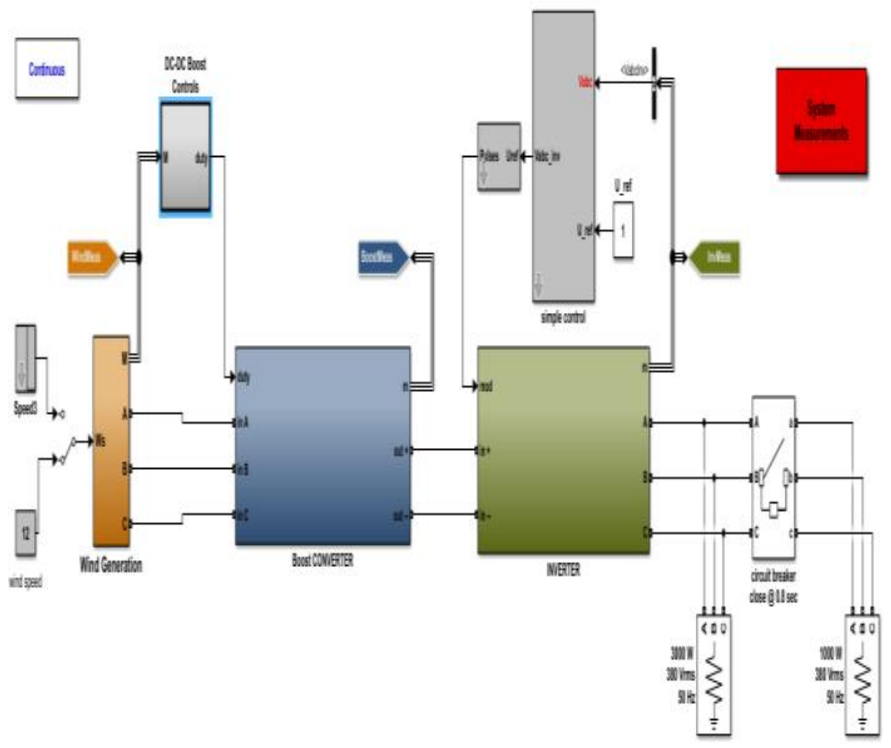

Fig. 10. Simulink model of the PMSG with boost converter and inverter.

\section{A. INC algorithum}

The simulation is run at $\mathrm{t}=0 \mathrm{~s}$ to $1 \mathrm{~s}$. At the beginning, the wind is set at 12 , at $\mathrm{t}=0.5 \mathrm{~s}$ a step change of wind to 8 , also at $0.8 \mathrm{~s}$ the extra load of $1000 \mathrm{w}$ added, is performed. Fig.11 represented the output power of the PMSG. Fig.12 is the output voltage of the PMSG with the step change of the wind speed. In Fig.13, the current of the PMSG changes when the wind speed changes.

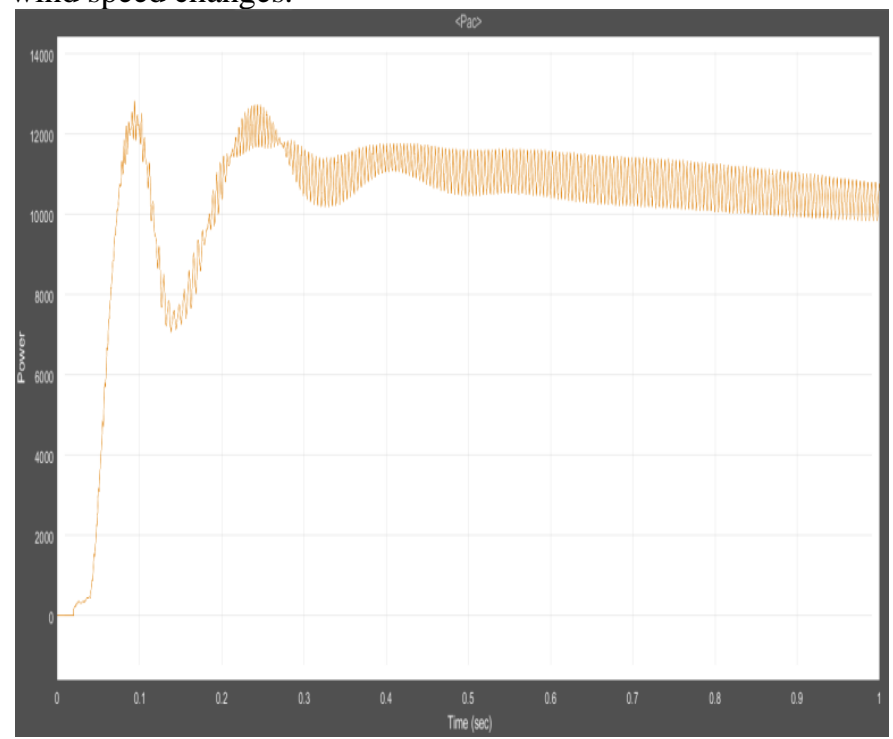

Fig. 11. PMSG power output using INC algorithum.

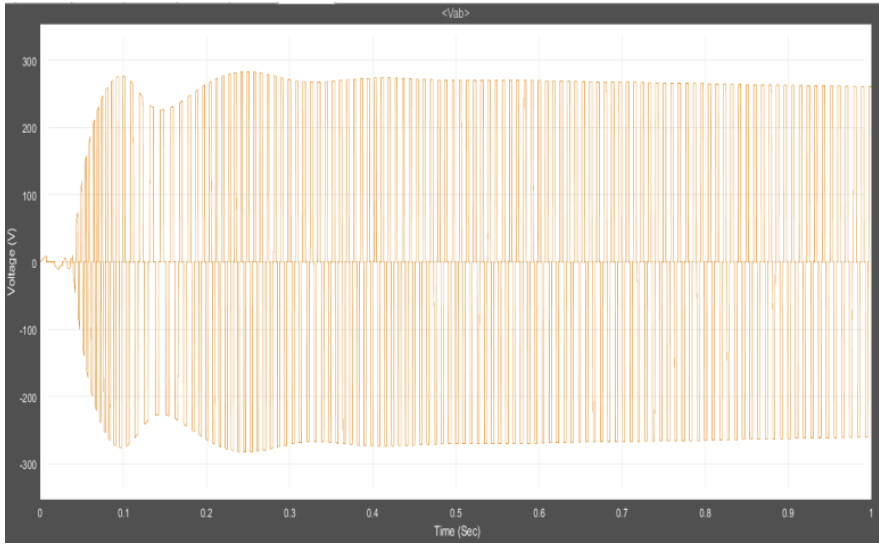

Fig. 12. PMSG output voltage using INC algorithum.

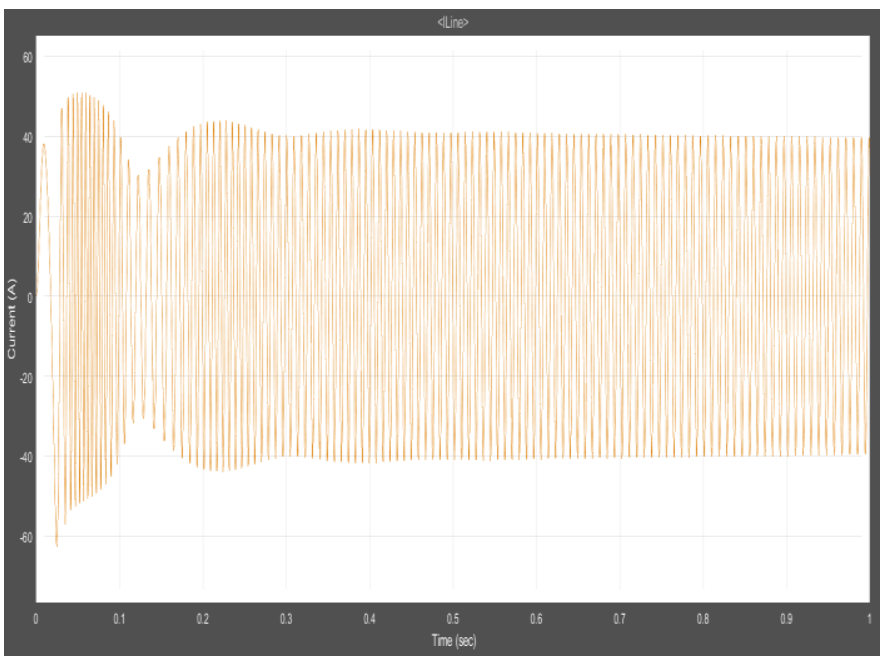

Fig. 13. PMSG output current using INC algorithum.

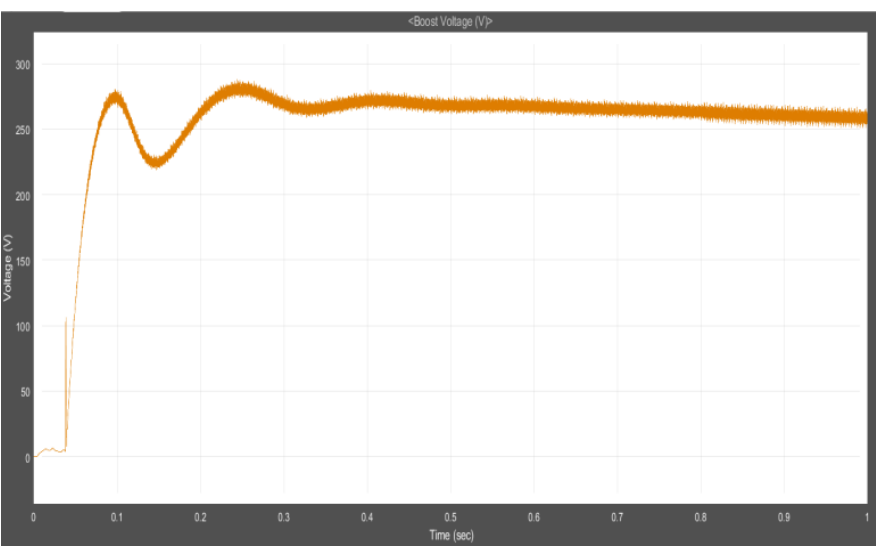

Fig. 14. Boost converter output voltage using INC algorithum.

In this simulation, the output of the boost converter is connected to the three-phase inverter and the three-phase variable resistive load. The INC MPPT controller still tracks the maximum power. The simulation model in Fig.11 is used to simulate the three-phase WECS with variable resistive loads. The three-phase inverter delivers a three-phase current to the load. Fig.16 shows sinusoidal output voltage and current of inverter as well output power of inverter. The DC voltage is converted into AC current to the load. 


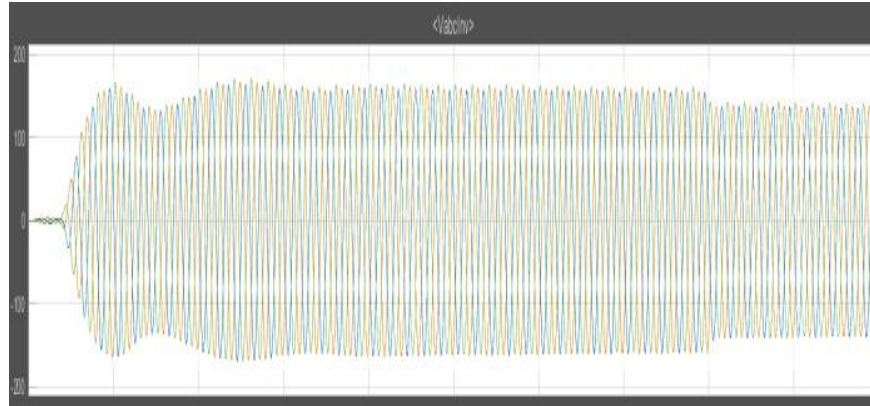

saters

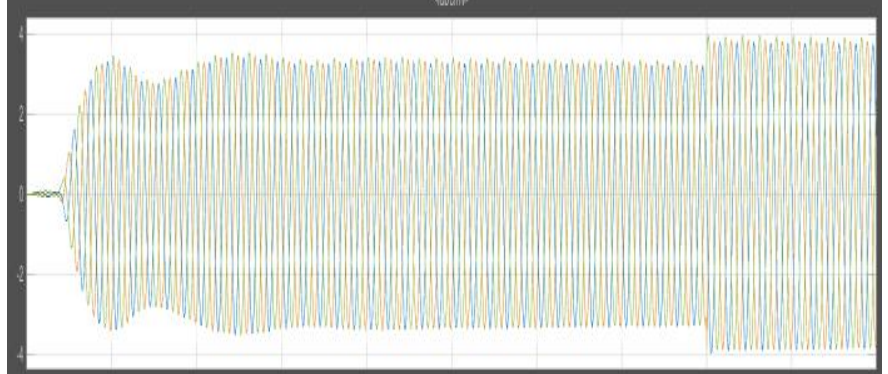

Golips

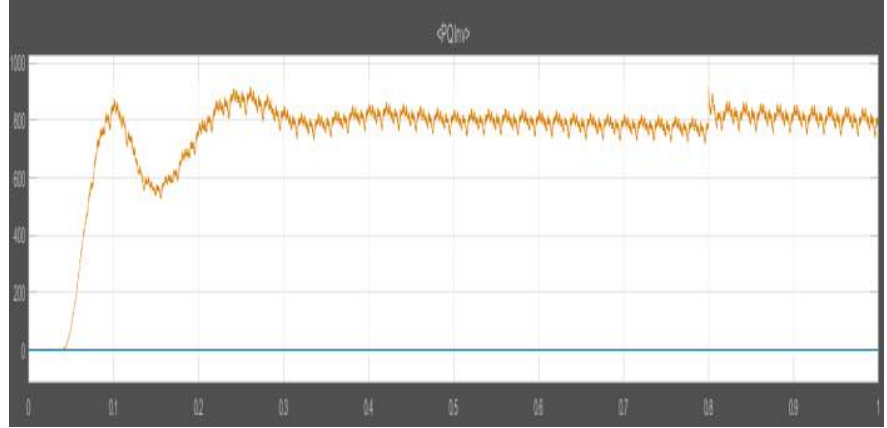

Fig. 15. Three phase inverter output voltage, current and power.

\section{B. PnO algorithum}

The simulation is run at $\mathrm{t}=0 \mathrm{~s}$ to $1 \mathrm{~s}$. At the beginning, the wind is set at 12 , at $\mathrm{t}=0.5 \mathrm{~s}$ a step change of wind to 8 , also at $0.8 \mathrm{~s}$ the extra load of $1000 \mathrm{w}$ added, is performed. Fig. 17 represented the output power of the PMSG. Fig. 18 is the output voltage of the PMSG with the step change of the wind speed. In Fig.19, the current of the PMSG changes when the wind speed changes.

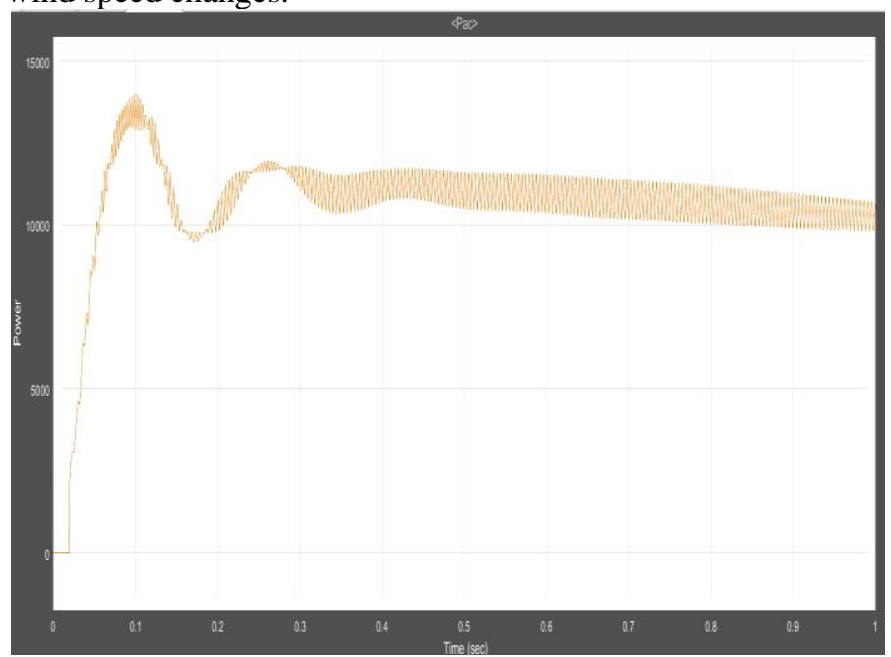

Fig. 16. PMSG output voltage using PnO algorithum.

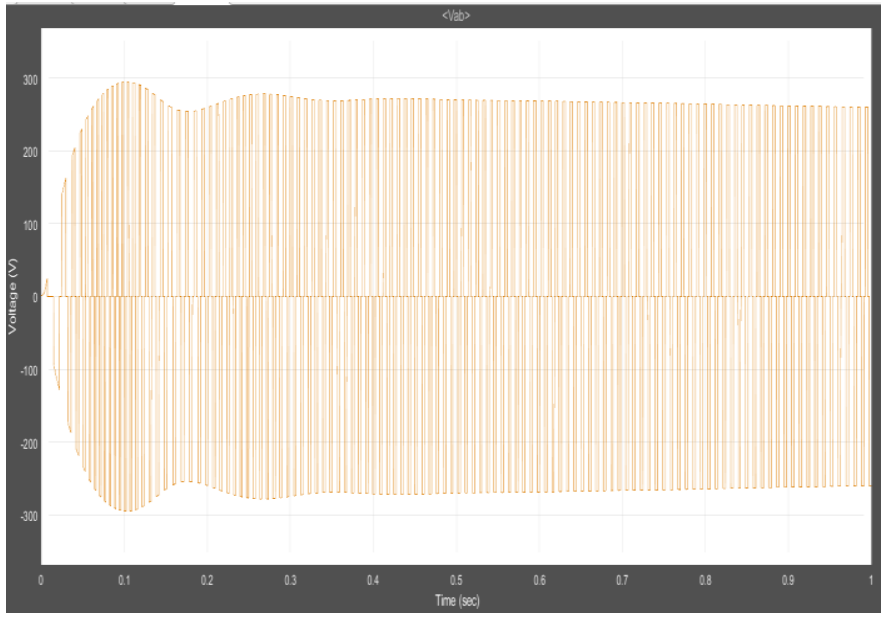

Fig. 17. AC measurement using PnO MPPT.

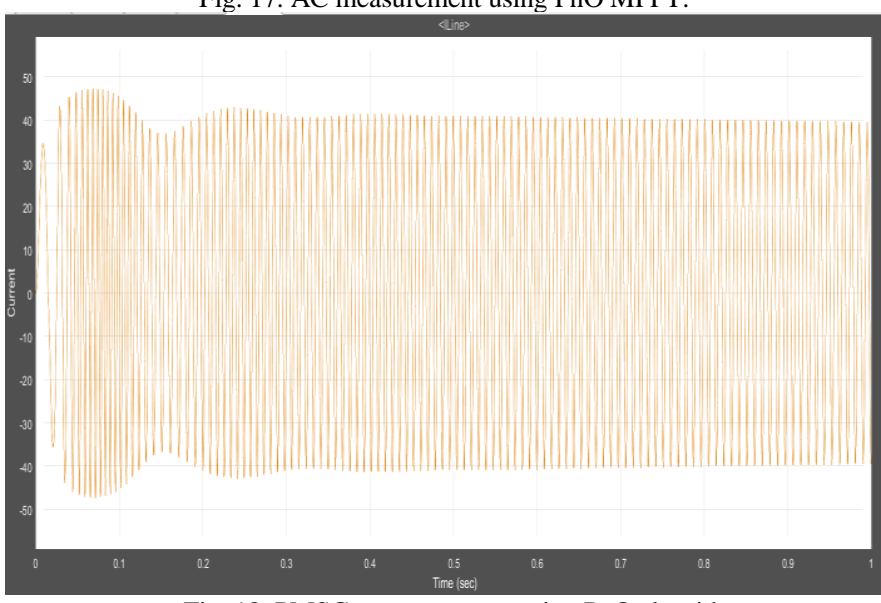

Fig. 18. PMSG output current using PnO algorithum.

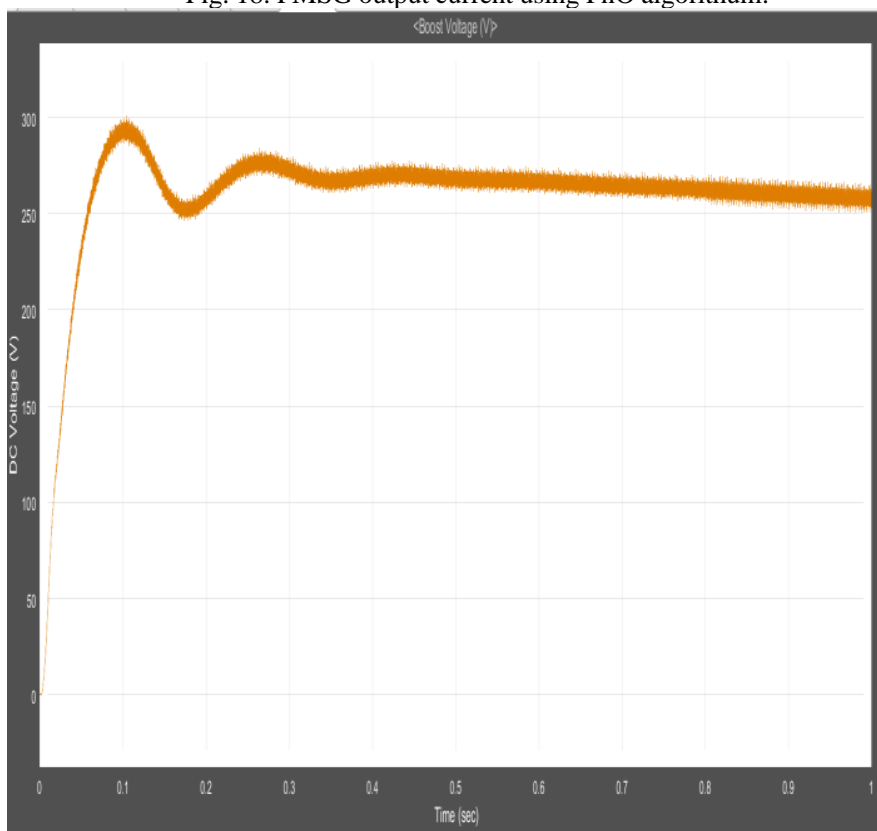

Fig. 19. Boost converter output voltage using $\mathrm{PnO}$ algorithum.

In this simulation, the output of the boost converter is connected to the three-phase inverter and the three-phase variable resistive load. The three-phase inverter delivers a three-phase current to the load. Fig.21 shows sinusoidal output voltage and current of inverter as well output power of 
inverter. The DC voltage is converted into AC current to the load.

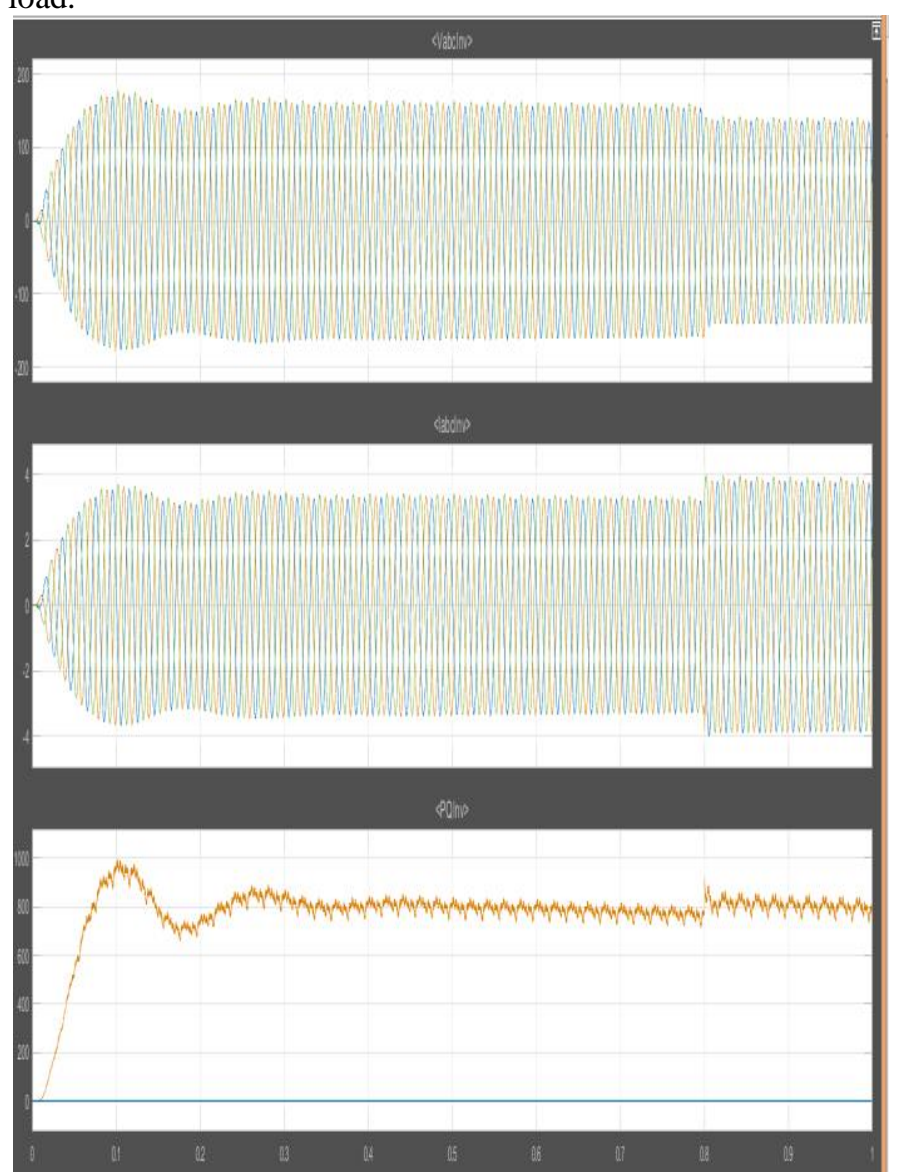

Fig. 20. AC measurement using PnO MPPT.

\section{CONCLUSION}

In this paper, the study of the WECS with maximum power point controller has been developed. From the theory of the WECS, a physical model of the WECS has been presented. Then, the wind generator system with DC-DC boost converter; maximum power point controller and resistive load have been designed. Finally, the system has been simulated with SIMULINK/MATLAB.

First, the simulations of the wind generation system showed that the simulated models were accurate to determine the characteristics voltage current because the current voltage characteristics are the same as the characteristics given from the data sheet. In addition, when the wind and load varies, the WECS models output voltage, current change. Then, the simulation showed that Perturb and observe algorithm can track the maximum power point of the WECS, it always runs at maximum power no matter what the operation condition is. The results showed that the Perturb and observe algorithm delivered an efficiency close to $100 \%$ in steady state.

The simulations of the WECS with maximum power point, boost converter and resistive load were performed by varying the load and the wind flow.

Finally, the WECS performance and the maximum power point were analyzed, and the three phase DC-AC inverter was simulated on a resistive load. The results showed that the DC voltage generated by the wind array could produce an AC current sinusoidal at the output of the inverter. The amplitude of the current depends on the wind turbine power.

\section{REFERENCES}

[1] U.S. Energy Information Administration (2016). International Energy Outlook. Washington, DC: U.S. Energy Information Administration.

[2] GWEC (2016). Global Wind 2016 Report. Washington, DC: Global Wind Energy Council (GWEC).

[3] Bansal, D., and Pandey, K. (2016). "Blade pitch angle and tip speed ratio control schemes for constant power generation of WECS," in Proceedings of 2016 IEEE 1st International Conference on Power Electronics, Intelligent Control and Energy Systems (ICPEICES), Delhi, 1-6.

[4] Enercon. Wind Turbine: Product Review. Aurich; Enercon.

[5] Nasiri, M., Milimonfared, J., and Fathi, S. H. "Modeling, analysis and comparison of TSR and OTC methods for MPPT and power smoothing in permanent magnet synchronous generator-based wind turbines", Elsevier J. Energy Conver. Manag. 86, 892-900,2014.

[6] Balasundar, C., Sudharshanan, S., and Elakkiyavendan, R. "Design of an optimal tip speed ratio control MPPT algorithm for standalone WECS”, Int. J. Res. Appl. Sci. Eng. Technol. 3, 442-450, 2015.

[7] Bouscayrol,A., Guillaud, X., Delarue, P., and Lemaire-Semail, B "Energetic macroscopic representation and inversion-based control illustrated on a wind-energy-conversion system using hardware-in-theloop simulation”, IEEE Trans. Ind. Electron. 56, 4826-4835,2009.

[8] Ibarra, E., Kortabarria, I., Andreu, J., Martinez de Alegria, I., Martin, J., and Ibanez, P. "Improvement of the design process of matrix converter platforms using the switching state matrix averaging simulation method" IEEE Trans. Ind. Electron. 59, 220-234, 2012.

[9] Haque, M. E., Negnevitsky, M., and Muttaqi, K. M. "A novel control strategy for a variable-speed wind turbine with a permanentmagnet synchronous generator", IEEE Trans. Ind. Appl. 46, 331-339, 2010.

[10] Morimoto, S., Kato, H., Sanada, M., and Takeda, Y. "Output maximization control for wind generation system with interior permanent magnet synchronous generator," in Proceedings of the 41th Conference Record IEEE IAS Annual Meeting, Tampa, Vol. 1, 503$510,2006$.

[11] Mahdavian, M., Wattanapongsakorn, N., Shahgholian, G., Mozafarpoor, S. H., Janghorbani, M., and Shariatmadar, S. M "Maximum power point tracking in wind energy conversion systems using tracking control system based on fuzzy controller," in Proceedings of 2014 11th International Conference on Electrical Engineering/Electronics, Computer, Telecommunications and Information Technology (ECTI-CON), Nakhon Ratchasima, 2014.

[12] Chien-Hung, L., and Yuan-Yih, H. "Effect of rotor excitation voltage on steady-state stability and maximum output power of a doubly fed induction generator. IEEE Trans. Ind. Electron. 58, 1096-1109, 2011

[13] Tan, K., and Islam, S. "Optimum control strategies in energy conversion of PMSG wind turbine system without mechanical sensors", IEEE Trans. Energy Convers. 19, 392-399, 2004

[14] Rahim, A. H. M. A. "Optimum relation based maximum power point tracking of a PMSG wind generator through converter controls," in Proceedings of the 7th IET International Conference on Power Electronics, Machines and Drives (PEMD 2014), Manchester, 1-6, 2014.

[15] Agarwal, V., Aggarwal, R. K., Patidar, P., and Patki, C. "A novel scheme for rapid tracking of maximum power point in wind energy generation systems", IEEE Trans. Energy Convers. 25, 228-236, 2010.

[16] Koutroulis, E. and Kalaitzakis, K. "Design of a maximum power tracking system for wind-energy-conversion applications", IEEE Trans. Ind. Electron. 53, 486-494, 2006.

[17] Patsios, C., Chaniotis, A., Rotas, M., Kladas, A. G. "A comparison of maximum power-point tracking control techniques for low-power variable-speed wind generators," Proceedings of the 8th International Symposium Advanced Electromechanical Motion System Electron Drives Jt Symposium, San Diego, CA, 1-3, 2009.

[18] Liu, C., Chau, K. T., and Zhang, X. "An efficient wind-photovoltaic hybrid generation system using doubly excited permanent magnet brushless machine", IEEE Trans. Ind. Electron., 57, 831-839, 2010.

[19] Kazmi, S. M. R., Goto, H., Hai-Jiao, G., and Ichinokura, O. "A novel algorithm for fast and efficient speed-sensorless maximum power poin tracking in wind energy conversion systems" IEEE Trans. Ind. Electron. 58, 29-36, 2011

[20] Femia, N., Petrone, G., Spagnuolo, G., and Vitelli, M. "Optimization of perturb and observe maximum power point tracking method", IEEE Trans. Power Electron. 20, 963-973, 2005. 
[21] Dalala, Z. M., Zahid, Z. U., Yu, W., Cho, Y and Lai, J. S. "Design and Analysis of an MPPT technique for small-scale wind energy conversion systems," IEEE Trans. Energy Convers. 28, 3, 2013.

[22] Xia, Y., Ahmed, K. H., and Williams, B. W. "A new maximum power point tracking technique for permanent magnet synchronous generator based wind energy conversion system", IEEE Trans. Power Electron. 26, 3609-3620, 2011.

[23] Abdullah, M. A., Yatim, A. H. M., Tan, C. W. "An online optimumrelation-based maximum power point tracking algorithm for wind energy conversion system," Australasian Universities Power Engineering Conference (AUPEC), Perth, 2014

[24] Zhang, H. B., Fletcher, J., Greeves, N., Finney, S. J., and Williams, B. W. "One-power-point operation for variable speed wind/tidal stream turbines with synchronous generators," IET Renew. Power Gener. 5, 99-108.

[25] Xia, Y., Ahmed, K. H., Williams, B. W. "A new maximum power point tracking technique for permanent magnet synchronous generator based wind energy conversion system", IEEE Trans Power Electron. 26, 3609-3620,2011.

[26] Petrila, D., Blaabjerg, F., Muntean, N., and Lascu, C. "Fuzzy logic based MPPT controller for a small wind turbine system" Proceedings of the 13th International Conference on Optimization of Electrical and Electronic Equipment (OPTIM), Brasov, 993-999,2012.
[27] Simoes, M. G., and Bose, B. K. "Design and performance evaluation of fuzzy-logic-based variable-speed wind generation system", IEEE Trans. Ind. Appl. 33, 956-965, 1997.

[28] Galdi, V., Piccolo, A., and Siano, P. "Designing an adaptive fuzzy controller for maximum wind energy extraction", IEEE Trans. Energy Convers. 23, 559-569, 2008

[29] Galdi, V., Piccolo, A., Siano, P. "Exploiting maximum energy from variable speed wind power generation systems by using an adaptive Takagi-Sugeno-Kang fuzzy model" Energy Convers. Manage. 50, 413-421,2009.

[30] Kyoungsoo, R., Han-ho, C., (2005). Application of neural network controller for maximum power extraction of a grid-connected wind turbine system. Elect. Eng. 88, 45-53.

[31] Li, H., Shi, K. L., and McLaren, P. G. (2005). Neural-network-based sensorless maximum wind energy capture with compensated power coefficient. IEEE Trans. Ind. Appl. 41, 6, 1548-1556.

[32] Huang, C., Li, F., Jin, Z. (2015). Maximum power point tracking trategy for large-scale wind generation systems considering wind turbine dynamics. IEEE Trans. Ind. Electron. 62, 4.

[33] Zhang, X., Huang, C., Hao, S., Chen, F., Zhai, J. (2016). An improved adaptive-torque-gain MPPT control for direct-driven PMSG wind turbines considering wind farm turbulences. Energies 9, 977.

[34] Wei, C., Zhang, Z., and Qu, L. (2016). An adaptive network-based reinforcement learning method for MPPT control of PMSG wind energy conversion systems. IEEE Trans. Power Electron. 31, 11. 